\section{Dr. Tebo, et al, reply}

\section{To the Editor:}

We read with great interest the response by Drs. Jearn and $\mathrm{Kim}^{1}$ to our letter "Presence of Anti-topoisomerase I Antibody Alone May Not Be Sufficient for the Diagnosis of Systemic Sclerosis" ${ }^{2}$. We agree with Drs. Jearn and Kim that the antinuclear antibody (ANA)-negative accompanied by antitopoisomerase I antibody (anti-topo I) positivity is not sufficient to diagnose systemic sclerosis (SSc). Although we noted an apparent association between relatively lower anti-topo I antibody levels (median $76 \mathrm{AU} / \mathrm{ml}$, range 42-118 $\mathrm{AU} / \mathrm{ml}$ ) and lung pathology in ANA-negative (6/11) or -positive (5/11) cases, we only suggested that our observation warrants further study. We did not state that the finding is clinically significant or that this pattern predicts pulmonary epithelial damage.

Our article was written to inform clinicians on practical clues in the interpretation of anti-topo I antibody results in routine clinical settings based on experience at our academic center. The observation that low anti-topo I antibody levels may be associated with lung pathology, though rare (11/3331, $0.3 \%$ ), was an incidental finding that warrants further investigation. We believe this was worth mentioning because, in clinical practice, physicians often order this autoantibody test sometimes without ANA for patients presenting with dyspnea.

The anti-topo I antibody (regardless of ANA positivity) is included in the 2013 classification criteria for $\mathrm{SSc}^{3}$. Clinicians often refer patients to rheumatology or pulmonary care based on the scenario we mentioned in our study. In the absence of harmonized diagnostic immunoassays for the detection of anti-topo I antibodies, our study highlights the importance of thorough assessment of a patient with physical examination and lung imaging if dyspnea is present, as well as ANA testing by the indirect immunofluorescence antibody (IFA) method. To be clear, the intent of ANA IFA screening to detect anti-topo I antibodies as suggested by the authors ${ }^{1}$ is not a common practice in the United States, where IFA patterns are generally reported. While guidance to detect anti-topo I antibody based on ANA IFA pattern has recently been reported, unreliability due to subjectivity in their interpretation and differences in the performance characteristics of commercially available ANA IFA reagents are known limitations ${ }^{4}$. It is very likely that correlation between specific ANA IFA patterns and autoantibody targets (i.e., anti-topo I) is highly dependent on the titer of the antibody, the epitope(s) bound, the type of antigen used in the immunoassay, or the antibody isotype/class or source of HEp-2 substrate ${ }^{4,5}$. Thus, in a real-world setting, the relationship between autoantibody specificity and ANA IFA pattern is not absolute.

We agree with Drs. Jearn and Kim regarding the potential limitations of the multiplex assay for detecting anti-topo I antibodies ${ }^{1}$. However, these are not limited to multiplex methodology as outlined in our letter and have been reviewed elsewhere ${ }^{5}$. Our unpublished data comparing results for anti-topo
I antibodies by the Theradiag multiplex bead assay and immunodiffusion (traditional method) using well-characterized US SSc samples $(n=445: 118$ anti-topo I antibody-positive by multiplex bead assay vs 119 by immunodiffusion and 318 anti-topo antibody-negative by multiplex bead assay vs 326 by immunodiffusion) showed excellent overall agreement of $98.0 \%$, with sensitivity and specificity relative to immunodiffusion of $99.2 \%$ and $97.5 \%$, respectively (data not shown). Of note, the median anti-topo I antibody level in the cohort was estimated at $147 \mathrm{AU} / \mathrm{ml}$, which is comparable to $158 \mathrm{AU} / \mathrm{ml}$ observed in the patients with SSc in our letter.

We found that significantly elevated anti-topo I antibody levels are strongly associated with a diagnosis of SSc when the ANA by IFA is positive. Of interest, we noted a possible association between lower anti-topo I antibody levels and lung pathology and suggested that this observation warrants further study. Given the progressive course of SSc, its clinical heterogeneity and high penetrance of lung pathology in anti-topo I antibodypositive patients, this association, if confirmed, could be clinically useful.

ANNE E. TEBO, PhD, ARUP Laboratories and Department of Pathology, University of Utah; ROBERT L. SCHMIDT, MD, PhD, ARUP Laboratories and Department of Pathology, University of Utah; TRACY M. FRECH, MD, Department of Rheumatology, University of Utah, Salt Lake City, Utah, USA. Address correspondence to Dr. T.M. Frech, Department of Rheumatology, University of Utah, 4b200 SOM 30 N. 1900 E., Salt Lake City, Utah 84132, USA. E-mail: tracy.frech@hsc.utah.edu

\section{REFERENCES}

1. Jearn LH, Kim TY. ANA-negative anti-topoisomerase I is not generally accepted. J Rheumatol 2019;46:1546.

2. Tebo AE, Schmidt RL, Frech TM. Presence of antitopoisomerase I antibody alone may not be sufficient for the diagnosis of systemic sclerosis. J Rheumatol 2019;46:440-2.

3. van den Hoogen F, Khanna D, Fransen J, Johnson SR, Baron M, Tyndall A, et al. 2013 classification criteria for systemic sclerosis: an American College of Rheumatology/European League against Rheumatism collaborative initiative. Arthritis Rheum 2013; 65:2737-47.

4. Andrade LEC, Klotz W, Herold M, Conrad K, Rönnelid J, Fritzler $\mathrm{MJ}$, et al. International consensus on antinuclear antibody patterns: definition of the AC-29 pattern associated with antibodies to DNA topoisomerase I. Clin Chem Lab Med 2018;56:1783-8.

5. Mahler M, Silverman ED, Schulte-Pelkum J, Fritzler MJ. Anti-Scl-70 (topo-I) antibodies in SLE: Myth or reality? Autoimmun Rev 2010;9:756-60.

First Release August 1 2019; J Rheumatol 2019;46:11; doi:10.3899/jrheum.190594 